\title{
General patients' expectations on online accessibility to their electronic health records in Japan
}

\author{
Lalla Soundous Elkhaili El Alami*, Asuka Nemoto, Yoshinori Nakata
}

Teikyo University Graduate School of Public Health, Tokyo, Japan.

\begin{abstract}
Allowing patients to access their electronic health records (EHR) online, that we call the patient openEHR, may help patients better understand and remember their health information, leading to improved health outcomes. In Japan, such solution is not yet widespread, and general patients' expectations for such solution are not known. The OpenNotes initiative in the United States of America (USA) had done various studies concerning the intervention of sharing doctors' notes, which are part of the EHR, with patients. Our study objective is to explore general patients' expectations toward potential benefits and risks of the patient open-EHR solution if given chance to use in Japan. A cross-sectional study was done using an online questionnaire. One hundred and eighty-three general patients without previous experience using the patient open-EHR service, responded to our survey after being recruited through SNS and posters at a university hospital not offering the solution. Comparison with the result of the OpenNotes original study, conducted in a similar setting, was also done. The results showed that participants were, similarly to the OpenNotes results, positive about the system's potential benefits; $90 \%$ agreed on the system ability to help them better understand their condition and remember their healthcare plan. On the other hand, they were much concerned about the potential risks especially privacy; $62 \%$ agreed they would be worried about their privacy. Adequate measures to provide highly secured systems and to allow patients to be better informed about the use of their personal health records should be taken to comfort future users.
\end{abstract}

Keywords: EHR, patient understanding, remembering, OpenNotes, privacy concern

\section{Introduction}

Healthcare Information Technology (HIT) is changing how the healthcare industry operates globally and has already begun to reduce waste and help improve health outcomes (1). Electronic health records (EHR) are major components of HIT. The use of EHR has the potential to facilitate patient access to personal records, test results, health education tools, and tools for tracking and assessing the progress of chronic disease management. In other countries, the impact of sharing electronic medical and health records with patients on different aspects of quality and safety of care was previously studied (2-6). A systematic review showed that patient online access to EHR and linked services offer increased convenience and satisfaction (4). However, health professionals were concerned about impact on workload and risk to privacy. Another systematic review article suggested that there was insufficient evidence about the effect of patient accessible EHRs on health outcomes for patients (5). Recently, new possibilities have arisen from innovative studies that enabled patients to read their physician notes, which are part of the EHR, online after the clinical encounter. The OpenNotes initiative had shown positive results concerning sharing doctors' notes with patients (7-9). After reviewing their visit notes, patients reported better understanding and remembering and feeling more in control of their care (9).

Many movements have started in Japan, about 20 years ago, to help and promote the sharing of EHR data between hospitals or medical institutions in the same region (10). Some of these regional networks allow the sharing of EHR data with patients online. However, the number of registered patients nationwide is still very low. Based on survey done by the Japan Medical Association Research Institute (JMARI) on these regional networks in March 2016, approximately 250 regional EHR networks are assumed to have existed nationwide and the number of registered patients at 154 of these networks was less than 1.2 million $(11,12)$. Out of these registered 1.2 million approximately 700,000 patients only get access to their EHR data.

In Japan, to the best of the authors' knowledge, there is limited research regarding the sharing of electronic medical and health records with patients $(13,14)$. A previous study on attitudes towards releasing medical information to patients with focus on ethical issues was done (13), which demonstrated that information raising 
ethical issues (i.e. child abuse) strongly influences the judgment of whether to release the records to patients or not. Another study focused on pregnant women's electronic medical records (EMR)-related needs (14). It showed that pregnant Japanese women want accessible and exchangeable EMRs with explanations and summaries.

The objective of the present study is to explore general patients' expectations toward potential benefits or risks of the patient open-EHR solution if given chance to use in Japan. Besides this, we investigated the relationship between respondents' characteristics and their views and also compared our results with those of the OpenNotes study before having doctors' notes shared with patients $(8)$.

\section{Materials and Methods}

\section{Overall design}

A cross-sectional study was done using an online questionnaire. The questionnaire we used was based on the survey done by the OpenNotes initiative original study conducted before having doctors' notes open to patients $(8)$. The questionnaire was prepared in both the English and Japanese languages. The one in English was to provide further convenience for foreign-origin residents in Japan, who are more familiar using English than Japanese. Questionnaires were conducted online by using SurveyMonkey. Respondents could skip individual questions or exit at any point. Responses up to the point of exit were used in the data analysis. Questionnaires were designed to take less than 20 minutes. No incentives were given to the respondents. The institutional review board of Teikyo University approved the overall project plan (Approval ID: TUIC-COI 18-0851).

\section{Participants}

Participants were recruited through the internet social networks (Facebook, LINE, mailing lists) and also at the Teikyo University Hospital that is not providing patient open-EHR service, by displaying a poster that invited patients to participate in the survey. Individuals 18 years old and older living in Japan who had previously accessed Japanese hospitals/clinics in the last one year were invited to participate. The first recruitment through social networks was done in November 2018 and through posters in the Teikyo University Hospital in April 2019. Answers collected until October 2019 were used in the analysis.

\section{Measurements}

Participants views on potential benefits (better understanding, remembering and others) and risks (privacy concern and others) of the patient open-EHR were investigated. Our key research questions asked about participants' views on the statements listed in Table 1. For statements 2-9 the question was "Imagine what it might be like to read your EHR online. If you could access your EHR online, would you agree or disagree with the statements below?". Participants could respond to each item on a five-point Likert scale, where the response choices ranged from "strongly disagree" to "strongly agree". Short expressions in Table 1 would be used when summarizing the results in later part of this paper. The following socio-demographic data were collected: age, gender, nationality, educational level, occupation, household income, satisfaction with present life, people living with, internet access tool, overall health status, previous diagnosis/treatment. The following items were also evaluated using already validated scales' questions as follow: $i$ ) patient preference for decision making (DM), measured using decision making preference scale (15); ii) health literacy (HL), measured using communicative and critical HL score (16); iii) patient trust in physician, measured using trust in physician score (17); and $i v$ ) patient ability to ask/understand/remember, using ask understand remember assessment (AURA) score (18).

\section{Statistical analysis}

For patient characteristics, categorical variables were presented as proportions, and continuous variables

Table 1. Key statements used in the survey

\begin{tabular}{llll}
\hline & & & Statement \\
Potential benefits & 1 & $\begin{array}{l}\text { In general, making EHR accessible to patients on a secure Internet website } \\
\text { or application is a good idea. }\end{array}$ & Good idea \\
& 2 & I would better understand my health and medical conditions. & Understand \\
& 3 & I would better remember the plan for my care. & Remember \\
& 4 & I would take better care of myself. & Take medication \\
& 5 & I would be more likely to take my medications as prescribed. & In control \\
Potential risks & 6 & I would feel more in control of my health care. & Prepared \\
& 7 & I would be better prepared for visits. & Worry \\
& 9 & I would worry more. & Privacy \\
& 10 & The EHR would be more confusing than helpful. & Confusing \\
\hline
\end{tabular}

EHR, electronic health record. 
were summarized with means and standard deviations or medians. Statements on potential benefits and risks were answered using a 5-level agree-disagree response set. The responses were dichotomized into agree category that combined the "agree" and "strongly agree" responses, and the other category that combined other responses. We examined the relationship between patient responses, on the benefits and risks of patient open-EHR, and patient characteristics, such as sex, age, education, health status, preference for decision making, health literacy and patient trust in physician. The chi-square test was used to examine the relationship between patient background information and the proportion of agree on the benefits or risks of the patient open-EHR with a significant level of 0.05 for a two-sided test. Statistical analysis software used was SAS 9.4. Comparison with the OpenNotes results was done using age-adjusted agree proportions on potential benefits and risks. Age was chosen because age was related to the agree proportions about potential benefits and because distributions of age were different in the two populations (the current study and the OpenNotes study).

\section{Results}

One hundred and sixty-six participants accessed the Japanese survey link and 70 the English survey link. Out of these respondents, 5 in the Japanese and 6 in the English previously used patient open-EHR service. From the remaining non-user respondents, we got 138 completed answers to our analysis questions in the Japanese survey and 45 completed answers in the English survey, making a total number of non-user respondents equal to 183.

Respondents' characteristics and their views regarding the potential benefits/risks results were shown in Table 2 and Table 3. The mean age of respondents was 41 years old. Attitudes of non-user respondents met our expectations; Most of respondents (86\%) were positive about the prospect of accessing freely their medical records online, regardless of demographics or health and other characteristics. 90\% agreed that the patient open-EHR would help them understand their health condition and remember their health plan. On the other hand, regarding worries on potential risks, we found a relatively high proportion worried on potential risks, especially privacy (62\%) (Table 3 ).

Tables 4-6 show results on the relationship between the agree proportion on some of the potential benefits (Understand and Remember) and risks (Privacy) of the patient open-EHR, and the patients characteristics listed below; sex, age, education, overall health, preference for decision making, health literacy and patient trust in physician. Only the relationship between age and agree proportion on Understand statement that was statistically significant ( $p=0.012$ ) (Table 4$)$. The agree proportion on Understand was low for respondents aged 50 and
Table 2. Non-user respondents' characteristics $(n=183)$

\begin{tabular}{|c|c|}
\hline Characteristic & Numerical value \\
\hline \multicolumn{2}{|l|}{ Age, $n(\%)$} \\
\hline $18-29$ & $19(10)$ \\
\hline $30-39$ & $66(36)$ \\
\hline $40-49$ & $73(40)$ \\
\hline $50-59$ & $19(10)$ \\
\hline $60-69$ & $3(2)$ \\
\hline 70 and above & $3(2)$ \\
\hline Female, $n(\%)$ & $127(69)$ \\
\hline \multicolumn{2}{|l|}{ Education, $n(\%)$} \\
\hline Elementary or junior high school & $0(0)$ \\
\hline High school & $6(3)$ \\
\hline Some college or 2-year degree & $21(12)$ \\
\hline 4-year university graduate & $79(43)$ \\
\hline Graduate school & $77(42)$ \\
\hline \multicolumn{2}{|l|}{ Overall health, $n(\%)$} \\
\hline Good & $62(34)$ \\
\hline Fairly good & $87(47)$ \\
\hline Fair & $23(13)$ \\
\hline Fairly poor & $10(5)$ \\
\hline Poor & $1(1)$ \\
\hline Smartphone users, $n(\%)$ & $171(93)$ \\
\hline \multicolumn{2}{|l|}{ Decision making preference score } \\
\hline Mean (SD) & $13.5(3.4)$ \\
\hline Median & 14 \\
\hline \multicolumn{2}{|l|}{ Communicative and critical HL score } \\
\hline Mean (SD) & $17.9(3.6)$ \\
\hline Median & 18 \\
\hline \multicolumn{2}{|l|}{ Trust in physician score } \\
\hline Mean (SD) & $15.7(2.7)$ \\
\hline Median & 16 \\
\hline \multicolumn{2}{|l|}{ AURA score } \\
\hline Mean (SD) & $12.7(2.3)$ \\
\hline Median & 12 \\
\hline
\end{tabular}

$\overline{\mathrm{SD} \text {, standard deviation; HL, health literacy; AURA, ask understand }}$ remember assessment.

Table 3. Agree proportion of non-user respondents about the potential benefits/risks $(n=183)$

\begin{tabular}{llr}
\hline Statement (short expression) & $n(\%)$ \\
\hline Potential benefits & Good Idea & $157(86)$ \\
& Understand & $165(90)$ \\
& Remember & $164(90)$ \\
& Self-care & $134(73)$ \\
& Take medication & $109(60)$ \\
& In control & $135(74)$ \\
Potential risks & Prepared & $143(78)$ \\
& Worry & $61(33)$ \\
& Privacy & $113(62)$ \\
& Confusing & $49(27)$ \\
\hline
\end{tabular}

above and also for young category aged 18-29.

We also compared our results with ones of the OpenNotes study (8) (Table 7). We chose to compare with the results of the patients from the adult medicine and HIV clinics at Harborview Medical Center (HMC) because this center did not have patient online portals at the beginning of the original study (8). In terms of demographic characteristics and self-reported health status of HMC patients, the mean age of participants was 49 years old, $24 \%$ of participants were women, $73 \%$ were with college degree and above and $27 \%$ self- 
Table 4. Relationship between the agree proportion of non-user respondents about the statement regarding Understand and respondents' characteristics $(n=183)$

\begin{tabular}{lrrr}
\hline Characteristic & $\begin{array}{c}\text { Total } \\
n\end{array}$ & $\begin{array}{c}\text { Agree } \\
n(\%)\end{array}$ & $p$ value \\
\hline Sex & & & 0.417 \\
$\quad$ Male & 56 & $52(93)$ & \\
$\quad$ Female & 127 & $113(89)$ & \\
Age & & & 0.012 \\
18-29 & 19 & $15(79)$ & \\
$30-39$ & 66 & $62(94)$ & \\
$40-49$ & 73 & $69(95)$ & \\
50 and above & 25 & $19(76)$ & \\
Education & & & 0.267 \\
Up to 2years college degree & 27 & $25(93)$ & \\
4-year university graduate & 79 & $68(86)$ & \\
$\quad$ Graduate school & 77 & $72(94)$ & \\
Overall health & & & 0.628 \\
$\quad$ Good/ Fairly good & 149 & $135(91)$ & \\
Fair & 23 & $21(91)$ & \\
Poor/ Fairly poor & 11 & $9(82)$ & \\
Decision making preference score & & & 0.234 \\
$\quad$ Low $(<10)$ & 22 & $20(91)$ & \\
Moderate (10 AND $\leq 16)$ & 127 & $117(92)$ & \\
High $(>16)$ & 34 & $28(82)$ & \\
Communicative and critical HL score & & & 0.453 \\
$\quad$ Low $(<15)$ & 32 & $30(94)$ & \\
High $(\geq 15)$ & 151 & $135(89)$ & \\
Trust in physician score & & & 0.561 \\
$\quad$ Low $(<15)$ & 60 & $53(88)$ & \\
High $(\geq 15)$ & 123 & $112(91)$ & \\
\hline
\end{tabular}

HL, health literacy.

Table 5. Relationship between the agree proportion of non-user respondents about the statement regarding Remember and respondents' characteristics $(n=183)$

\begin{tabular}{|c|c|c|c|}
\hline Characteristic & $\begin{array}{c}\text { Total } \\
n\end{array}$ & $\begin{array}{l}\text { Agree } \\
n(\%)\end{array}$ & $p$ value \\
\hline Sex & & & 0.669 \\
\hline Male & 56 & $51(91)$ & \\
\hline Female & 127 & $113(89)$ & \\
\hline Age & & & 0.481 \\
\hline $18-29$ & 19 & $17(90)$ & \\
\hline $30-39$ & 66 & $62(94)$ & \\
\hline $40-49$ & 73 & $64(88)$ & \\
\hline 50 and above & 25 & $21(84)$ & \\
\hline Education & & & 0.990 \\
\hline Up to 2years college degree & 27 & $24(89)$ & \\
\hline 4-year university graduate & 79 & $71(90)$ & \\
\hline Graduate school & 77 & $69(90)$ & \\
\hline Overall health & & & 0.580 \\
\hline Good/Fairly good & 149 & $132(89)$ & \\
\hline Fair & 23 & $22(96)$ & \\
\hline Poor/Fairly poor & 11 & $10(91)$ & \\
\hline Decision making preference score & & & 0.512 \\
\hline Low $(<10)$ & 22 & $19(86)$ & \\
\hline Moderate $(10$ AND $\leq 16)$ & 127 & $116(91)$ & \\
\hline $\operatorname{High}(>16)$ & 34 & $29(85)$ & \\
\hline Communicative and critical HL score & & & 0.399 \\
\hline Low $(<15)$ & 32 & $30(94)$ & \\
\hline $\operatorname{High}(\geq 15)$ & 151 & $134(89)$ & \\
\hline Trust in physician score & & & 0.691 \\
\hline Low $(<15)$ & 60 & $53(88)$ & \\
\hline $\operatorname{High}(\geq 15)$ & 123 & $111(90)$ & \\
\hline
\end{tabular}

HL, health literacy.
Table 6. Relationship between the agree proportion of non-user respondents about the statement regarding Privacy and respondents' characteristics $(n=183)$

\begin{tabular}{lrrr}
\hline Characteristic & $\begin{array}{r}\text { Total } \\
n\end{array}$ & $\begin{array}{c}\text { Agree } \\
n(\%)\end{array}$ & $p$ value \\
\hline Sex & & & 0.890 \\
$\quad$ Male & 56 & $35(63)$ & \\
Female & 127 & $78(61)$ & \\
Age & & & 0.063 \\
$\quad 18-29$ & 19 & $15(79)$ & \\
$30-39$ & 66 & $46(70)$ & \\
$40-49$ & 73 & $39(53)$ & \\
50 and above & 25 & $13(52)$ & \\
Education & & & 0.959 \\
Up to 2years college degree & 27 & $16(59)$ & \\
4-year university graduate & 79 & $49(62)$ & \\
$\quad$ Graduate school & 77 & $48(62)$ & \\
Overall health & & & 0.988 \\
$\quad$ Good/Fairly good & 149 & $92(62)$ & \\
Fair & 23 & $14(61)$ & \\
Poor/Fairly poor & 11 & $7(64)$ & \\
Decision making preference score & & & 0.453 \\
$\quad$ Low $(<10)$ & 22 & $15(68$ & \\
Moderate (10 AND $\leq 16)$ & 127 & $80(63)$ & \\
High $(>16)$ & 34 & $18(53)$ & \\
Communicative and critical HL score & & & 0.923 \\
$\quad$ Low $(<15)$ & 32 & $20(63)$ & \\
High $(\geq 15)$ & 151 & $93(62)$ & \\
Trust in physician score & & & 0.507 \\
Low $<15)$ & 60 & $35(58)$ & \\
High $(\geq 15)$ & 123 & $78(63)$ & \\
\hline
\end{tabular}

HL, health literacy.

Table 7. Comparison of age-adjusted agree proportion about the potential benefits/risks with the OpenNotes results $(8)$

\begin{tabular}{lcc}
\hline Statement & $\begin{array}{c}\text { Non-users in Japan } \\
n=183(\%)\end{array}$ & $\begin{array}{c}\text { OpenNotes } \\
n=272(\%)\end{array}$ \\
\hline $\begin{array}{l}\text { Potential benefits } \\
\text { Good idea }\end{array}$ & $162(89)$ & $264(97)$ \\
$\quad$ Understand & $154(84)$ & $256(94)$ \\
Remember & $159(87)$ & $256(94)$ \\
Self-care & $129(71)$ & $231(85)$ \\
$\quad$ Take medication & $103(57)$ & $193(71)$ \\
In control & $111(61)$ & $261(96)$ \\
$\quad$ Prepared & $137(75)$ & $248(91)$ \\
Potential risks & & \\
$\quad$ Worry & $46(25)$ & $35(13)$ \\
$\quad$ Privacy & $103(56)$ & $95(35)$ \\
Confusing & $41(22)$ & $38(14)$ \\
\hline
\end{tabular}

reported fair or poor health status. Our survey results on respondents' views were represented using age-adjusted proportions. Despite the differences in proportions' values shown in Table 7 , we found a similar trend in both groups; positiveness about the potential benefits and some worries about the potential risks, from which worries on privacy were not negligible for both groups.

\section{Discussion}

The present results met our expectations; similarly to 
the US, most respondents to our survey in Japan were positive about the prospect of accessing freely their EHR online. Most agreed that this access could help improving their understanding of health and medical condition and remembering the care plan (Table 3 ). This suggests that the EHR could be used not only to share information between hospitals but also with patients. Such solution could contribute to further enhancing the efficiency of the communication between doctor and patient by improving patient's understanding and remembering of information received during the consultation.

In our results, the percentage of 'Agree' on Understand statement varied by age group. A smaller proportion of old participants aged 50 and above agreed on Understand statement (Table 4). This might be because older people could be still reluctant to ICT solutions. Therefore, this category of patients might need to try first in order to get convinced about the benefits of such solution. The proportion in young category aged 18-29 was slightly low as well (Table 4), this could be because younger subjects generally do not feel difficulty in understanding their health and medical conditions due to their limited experiences in complicated conditions.

Worries on potential risks especially privacy were not negligible independently of patients' characteristics (Table 3 and Table 6). In order to comfort future users, it will be required to provide highly secured systems that allow the protection of private health information and to explain to patients the measures taken. Moreover, many patients might still not feel comfortable with the idea that hospitals would disclose their private health information to other hospitals without knowing exactly what data are disclosed. Giving access to patients through the patient open-EHR and giving them the right to see and select exactly the data to share with other hospitals might help in further comforting patients about their privacy since they would feel in control of what happens to own health data.

Privacy worries are common with the US and other countries in Europe as well. In order to address such worries, the European Union adopted in 2016 a new regulation on the protection of personal data, also known as the EU General Data Protection Regulation (GDPR). This regulation provides more rights to citizens to be better informed about the use of their personal data and gives clearer responsibilities to people and entities using personal data (19). Clear and simplified guides were published to inform patients on their rights (20). In the US, the Department of Health \& Human Services (HSS), based on the requirement of the Health Insurance Portability and Accountability Act of 1996 (HIPAA), had developed and published the HIPAA Privacy Rule and the HIPAA Security Rule in order to protect the privacy and security of certain health information. The Privacy rule states clearly the rights each patient has over own health information (whether electronic, written, or oral) and sets rules and limits on who can look at and receive this health information (21). In order to help patients easily understand their rights, a series of short, educational videos were also developed and published in the HSS homepage (21).

In Japan, the Ministry of Health Labor and Welfare (MHLW) has also developed regulations and guidelines regarding the security management of health information systems (22). Regarding Privacy, the MHLW has also set guidelines for appropriate handling of personal information by medical and nursing care providers (23). However, to the authors' knowledge no clear information targeting patients themselves to inform them about their rights was published so far by the regulators in Japan. Increased worries regarding privacy as shown in our survey results (Table 3 and Table 6) could be explained by the lack of clear information on patients' rights regarding their electronic health records. Providing clear and easily understandable information to patients of different categories is needed in Japan.

Our study has some limitations. First, our survey was conducted online and results may not represent the overall population. However, since the solution is ICT based, we expect its future users will be similar to the respondents of this survey, who are familiar with computers and the internet. Second, we did not perform testing to evaluate reliability or validity of the questions that were taken from the questionnaire used in the OpenNotes study. However, after translation we did multi-check and testing with a small group before launching the survey.

In conclusion, needs and high expectations regarding the patient open-EHR solution were visualized through our study targeting non-user general patients in Japan. Such solution could bring benefits toward improving doctor-patient communication efficiency and patient satisfaction. The concern on privacy is a major barrier that should be addressed in order to comfort and encourage future users of the solution. Clear information targeting patients on their rights regarding their electronic health information should be made public as well. On the other hand, doctors' attitudes toward such solution should be also addressed in future studies.

\section{Acknowledgements}

Our sincere thanks go to Mrs. Janice Walker, co-founder of the OpenNotes initiative and assistant professor at Beth Israel Deaconess Medical Center for providing her great support and sharing with us the surveys questions used in the original study of the OpenNotes and providing insightful comments to our research. We also thank Prof. Kazue Yamaoka and Prof. Hirono Ishikawa, at the Teikyo University School of Public Health, for their great support in creating the questionnaire of this study. 


\section{References}

1. Health care information systems: a practical approach for health care management (Wager K, Lee F, Glaser J). John Wiley \& Sons, 2017; pp. 3-20.

2. Kruse C, Stein A, Thomas H, Kaur H. The use of Electronic Health Records to Support Population Health: A Systematic Review of the Literature. J Med Syst. 2018; 42:214.

3. White A, Danis M. Enhancing Patient-Centered Communication and Collaboration by Using the Electronic Health Record in the Examination Room. JAMA. 2013; 309:2327-2328.

4. De Lusignan S, Mold F, Sheikh A, et al. Patients' online access to their electronic health records and linked online services: a systematic interpretative review. BMJ Open. 2014; 4:e06021.

5. Jilka S, Callahan R, Sevdalis N, Mayer E, Darzi A. "Nothing about me without me": an interpretative review of patient accessible electronic health records. J Med Internet Res. 2015; 17:e161.

6. Neves A, Carter A, Freise L, Laranjo L, Darzi A, Mayer E. Impact of sharing electronic health records with patients on the quality and safety of care: a systematic review and narrative synthesis protocol. BMJ Open. 2018; 8:e020387.

7. OpenNotes website. https://www.opennotes.org (Accessed August 15, 2019).

8. Walker J, Leveille SG, Ngo L, Vodicka E, Darer JD, Dhanireddy S, Elmore JG, Feldman HJ, Lichtenfeld MJ, Oster N, Ralston JD, Ross SE, Delbanco T. Inviting patients to read their doctors' notes: patients and doctors look ahead: patient and physician surveys. Ann Intern Med. 2011; 155:811-819.

9. Delbanco T, Walker J, Bell SK, Darer JD, Elmore JG, Farag N, Feldman HJ, Mejilla R, Ngo L, Ralston JD, Ross SE, Trivedi N, Vodicka E, Leveille SG. Inviting Patients to Read Their Doctors' Notes: A Quasi-experimental Study and a Look Ahead. Ann Intern Med. 2012; 157:461470.

10. Yoshihara H. Millennial Medical Record Project: toward establishment of authentic Japanese version EHR and secondary use of medical data. Journal of Information Processing and Management. 2018; 60:767-778.

11. JMARI. Overview of report on regional EHR networks website. http://www.jmari.med.or.jp/research/working/ wr_605.html (Accessed August 10, 2019) (in Japanese).

12. JMARI. Report on EHR networks in Japan website. http:// www.jmari.med.or.jp/download/WP368.pdf (Accessed August 10, 2019) (in Japanese).

13. Amano H, Fujiwara N, Miyaji M, Kato K, Katsuyama K, Kobayashi S, Yamada K, Goto K, Otsubo M. A survey on attitudes towards releasing medical information including ethical issues. Japan Journal of Medical Informatics. 2008; 28:197-211. (in Japanese).

14. Helou S, Abou-Khalil V, Yamamoto G, Kondoh E, Tamura H, Hiragi S, Sugiyama O, Okamoto K, Nambu M,
Kuroda T. Understanding the EMR-related experiences of pregnant Japanese women to redesign antenatal care EMR systems. Informatics. 2019; 6:15.

15. Ende J, Kazis L, Ash A, Moskowitz M. Measuring patients' desire for autonomy: decision making and information-seeking preferences among medical patients. J Gen Intern Med. 1989; 4:23-30.

16. Ishikawa H, Nomura K, Sato M, Yano E. Developing a measure of communicative and critical health literacy: A pilot study of Japanese office workers. Health Promot Int. 2008; 23:269-274.

17. Dugan E, Trachtenberg F, Hall M. Development of abbreviated measures to assess patient trust in a physician, a health insurer, and the medical profession. BMC Health Serv Res. 2005; 5:64.

18. Clayman M, Pandit A, Bergeron A, Cameron K, Ross E, Wolf M. Ask, understand, remember: a brief measure of patient communication self-efficacy within clinical encounters. J Health Commun. 2010; 15 Supple 2:72-79.

19. European Commission. Data Protection in the EU. https:// ec.europa.eu/info/law/law-topic/data-protection/dataprotection-eu_en (Accessed March 1, 2020).

20. European Patients Forum. The new EU Regulation on the protection of personal data: what does it mean for patients? A guide for patients and patients' organizations. https:// www.eu-patient.eu/globalassets/policy/data-protection/ data-protection-guide-for-patients-organisations.pdf (Accessed March 1, 2020).

21. US Department of Health \& Human Services. Your Rights Under HIPAA. https://www.hhs.gov/hipaa/forindividuals/guidance-materials-for-consumers/index.html (Accessed March 1, 2020).

22. Ministry of Health, Labour and Welfare. Guidelines on health information systems security management. https://www.mhlw.go.jp/file/05-Shingikai12601000-Seisakutoukatsukan-Sanjikanshitsu_ Shakaihoshoutantou/0000166260.pdf (Accessed March 8, 2020) (in Japanese).

23. Ministry of Health, Labour and Welfare. Guidelines for appropriate handling of personal information by medical and nursing care providers website. https://www. mhlw.go.jp/stf/seisakunitsuite/bunya/0000027272.html (Accessed August 10, 2019) (in Japanese).

Received March 20, 2020; Revised June 6 2020; Accepted June 8, 2020.

Released online in J-STAGE as advance publication June 13, 2020.

*Address correspondence to:

Lalla Soundous Elkhaili El Alami, Teikyo University Graduate School of Public Health, 2-11-1 Kaga, Itabashi-Ku, Tokyo 1738605, Japan.

E-mail: soundous.elalami@gmail.com 